\title{
Seeing is believing: the capacity of the manipulated photograph to represent scenes of mythology and the supernatural
}

\author{
Carolyn Lefley
}

\begin{abstract}
This illustrated paper explores the capacity of the manipulated photograph to represent scenes of mythology and the supernatural. Can a photograph, which is said to be an index of the real, render a mythical realm into a believable scene? Practices such a double exposures and combination printing have historically been used to create famous faked images of the supernatural, such as the Cottingley Fairies images and the 'Surgeon's photograph' of the Loch Ness monster. Photography has a causal link with reality and as such a carefully manipulated image has the power to deceive or persuade the viewer.
\end{abstract}

In her photography project 'Realm' Carolyn Lefley explores this apparent truthtelling phenomenon by constructing double exposure photographs that create a layering of realities. A familiar domestic interior and a potentially mythological landscape combine to create scenes of make-believe, which reference texts such as Alice in Wonderland and The Lion, The Witch and the Wardrobe. Down the rabbit hole, through the looking glass and into the wardrobe, all of these paths lead from the realm of the real, into the realm of myth. The kingdom of Narnia is entered through an ordinary wardrobe. The photograph of a homely interior (the real) becomes a portal into a mythical realm (the unseen).

The photographs in 'Realm' depict new image-worlds that occupy a liminal space between reality and mythology. Digital post-production techniques have been utilised to achieve these multi-layered images. The paper will conclude with a consideration of the next era in photography, that of computer simulated reality.

Key Words: Photography, fake, mythology, supernatural, photoshop, cgi, manipulation, retouching.

$* * * * *$

\section{Photography and reality}

This illustrated paper explores the capacity of the manipulated photograph to represent scenes of mythology and the supernatural. Can a photograph, which is said to be an index of the real, render a mythical realm into a believable scene? Practices such as constructed photography, double exposures and combination printing have historically been used to create famous faked images of the supernatural, such as the Cottingley Fairies images and the 'Surgeon's photograph' 
of the Loch Ness monster. Photography has a causal link with reality and as such a carefully manipulated image has the power to deceive or persuade the viewer.

This paper begins with a consideration of the ontology of the constructed or manipulated photograph. The second part of the paper will comprise of a case study, which discusses my photography project 'Realm', a series of double exposure photographs. These images create a layering of spaces: the real, experienced space of the 'home' and the sites of myth or the unseen. In this work I play with the relationship between the believable space of the photographic image and sites of folklore. The paper will conclude with a consideration of the next era in photography, that of computer simulated reality, to aid visual deception.

Since its invention in the early nineteenth century photography has captivated viewers for its indexical qualities. Susan Sontag in her book On Photography, notes:

...a photograph is not only an image (as a painting is an image), and interpretation of the real, it is also a trace, something directly stencilled off the real, like a footprint or a death mask. ${ }^{1}$

Sontag's notion of the photograph as a trace or imprint of reality suggests that photography, more than any other man-made visual artefact, has an inherent quality of the 'real'. Andre Bazin in The Ontology of the Photographic Image notes:

Photography affects us like a phenomenon in nature, like a flower or a snowflake whose earthly origins are an inseparable part of their beauty. This production by automatic means has radically affected our psychology of the image... In spite of any objections our critical spirit may offer, we are forced to accept as real the existence of the object reproduced. ${ }^{2}$

Bazin makes a key point: since the process of taking photograph is mediated via a machine pointed at reality, our potentially doubting eyes may accept even the most unlikely scenes as fact. When attempting to illustrate myth or the supernatural artists and amateur image-makers have turned to the photograph to convince audiences.

In the early twentieth century, in part encouraged by J. M. Barrie's 1904 play Peter Pan, public interest in fairies was renewed. Between 1917 and 1920 five photographs were taken in Cottlingley, Yorkshire, which purported to depict fairies in the natural landscape. These images are now known to be fake and constructed for the camera, using cardboard cut-out fairies. This series of images have been labelled the 'Cottingley Fairies' photographs. Cousins, Frances Griffiths and Elsie Wright, who were both children at that time and not trained photographers, took these photographs. The five photographs, shot with a plate camera, show the girls 
taking turns to pose next to groupings of fairies and a goblin in one photograph. The last photograph in the series just shows the fairies without the human form. Their youth and amateurism gave rise to public opinion that these where authentic images and not a professional hoax. This series was published in 1920 when The Strand Magazine commissioned the author Arthur Conan Doyle to write the article 'An Epoch Making Event - Fairies Photographed'. Conan Doyle was convinced of the authenticity of the photographs and published a book in 1921, The Coming of the Fairies, which documents evidence for and against the images' veracity. In the preface of this book he appeals to critics and doubters of these images, that they are not the work of 'some professional trickster, apt at the art of deception'. ${ }^{3}$ Conan Doyle attested that the Cottingley Fairies photographs were the innocent work of two trustworthy children. Respected photography specialists inspected the original photographic plates and found no evidence of manipulation of the image or of double exposure. ${ }^{4}$ Professionals from Kodak Limited were also unable to find any flaws in the plates, but did not want to publically testify to their authenticity. ${ }^{5}$ To a modern viewer these images immediately look like constructed scenes, however the possibility of staging these photographs was discounted or overlooked. This reading of these pictures needs to be contextualised in an era when photography was generally unquestioned by the viewer.

The cousins from Cottingley only revealed these photographs to be a hoax when Ellie Wright gave a confessional interview in 1981, over sixty year after they had been published. This revelation came shortly after it had been suggested that the fairies bore a striking resemblance to the figures drawn in Princess Mary's Gift Book, published in 1915. In her confession Wright acknowledges they had in fact copied the illustrations in this book, and cut these out to photograph them. ${ }^{6}$

Wright and Griffiths staged these scenes to create an alternative reality, which arguably believable because of the very ontological nature of a photograph. Another famous faked photograph of a different kind of supernatural creature was also believed for decades. In 1934, the now infamous image of the Loch Ness monster, purported to be taken by British surgeon, Robert Wilson, was printed in the national press. The black and white grainy image showed what appeared to be a sea-serpent head breaking the surface of the rippling open water of Loch Ness. Though sceptics doubted the authenticity of this image it was only proved to be a hoax 60 years after it was published, when in 1994 Alastair Boyd and David Martin uncovered how the image was created. ${ }^{7}$ A few years previously one of the team that created the image, Christian Spurling, confessed to Boyd and Martin, that the 'monster' was actually a toy submarine with an attached sea-serpent head, modelled from plastic wood. ${ }^{8}$

The image originally printed in 1934 was heavily cropped to make the monster appear more threatening. The image was most probably readily accepted by the general public because of the honorific value ascribed to it by its inclusion in the national press and the respected profession of the photographer. The 'Surgeon's 
photograph' was for many sufficient evidence of the existence of a monster. The tradition of faked Loch Ness monster photographs continues: in 2013 local skipper George Edwards took a new hoax image using a model of 'Nessie' used in a recent documentary film. ${ }^{9}$ It might be quite telling that the official Loch Ness tourist body, which no doubt relishes each new Loch Ness monster photograph and sighting, even uses the slogan 'Seeing is believing'. ${ }^{10}$

At around the same time as the 'Surgeon's Photograph' was originally published, artists in the Surrealist movement where also experimenting with the medium of photography. Surrealists René Magritte, Man Ray, and Maurice Tabard used techniques such as double exposure, combination printing and photomontage to create dream-like photographs. They were fascinated by the duality of photographs that can represent reality and dream simultaneously. Sontag goes further to suggest that all photography is surreal, even those images that have no artistic trickery involved, such as double exposures. Sontag notes:

Surrealism lies at the heart of the photographic enterprise: in the very creation of a duplicate world, of a reality in the second degree, narrower but more dramatic than the one perceived by natural vision. ${ }^{11}$

The visual language of Hollywood has influenced contemporary photographers who create otherworldly images, which are often crafted in a film studio environment or with elaborate location lighting. American photographer Gregory Crewdson creates photographic tableau pictures, portraying the darker side of suburbia. Referencing the visual style of David Lynch and Stephen Spielberg, Crewdson's use of lighting suggests supernatural happenings. In his series Twilight (2001-2002), Crewdson photographs small town American at dusk, the hour of the gloaming, when all that is familiar becomes strange. One image from this series features a quiet suburban street at twilight, with a beam of light from the sky pointing at a patch of ground. The scene suggests a 'close encounter' or a potentially extra-terrestrial radiance from above. The familiar street becomes unfamiliar, referencing Sigmund Freud's idea of Das Unheimliche, the unhomely or uncanny. Freud defines the 'uncanny' as: 'that class of the terrifying which leads back to something long known to us, once very familiar'. ${ }^{12}$

Crewdson's photographs represent the supernatural within the banal, by his use of dramatic lighting and a Hollywood aesthetic. Through construction in front of the camera, trickery in the darkroom or using computer software, the photograph has the capacity to persuade and convict the viewer of limitless representations of fictional stories, supernatural tales and myth.

\section{Case Study: 'Realm'}

My photography project 'Realm' began life in 2009 as a practice based enquiry into belief and myth, exploring the capacity of a photograph to show or suggest the 
unseeable. I was interested in the relationship between belief and the photograph. I looked into past traditions of the British Isles and the rich tradition of myth in relation to the landscape. I define myth in this context as: 'a traditional story, explaining a natural or social phenomenon, typically involving supernatural beings or events'. ${ }^{13}$ I researched stories of folklore and fable that had taken place in the British Isles, and visited sites credited with supernatural events. I was particularly interested in photographing landscapes in which the local population had at some stage believed something mythological had occurred there. Image 1 shows one of my photographs at an early stage of the project, in 2009.

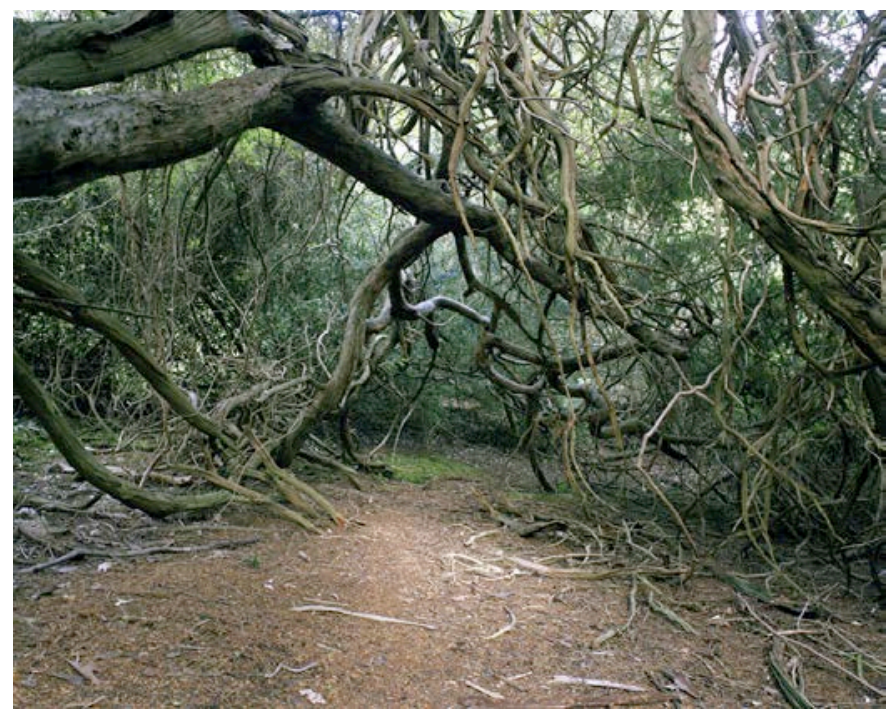

Image 1 - Carolyn Lefley, 'Yew trees at Kingley Vale', 2009. Reproduced with permission from the artist.

This yew forest contains a grove of ancient trees, which are believed to be around 2000 years old. The yew trees at Kingley Vale, in Surrey, hold particular interest because of the folklore that is entangled in their long history. This area is thought to be the site of a Viking invasion in which the local villagers triumphed, and the grove of ancient yew trees is supposedly planted over these Viking graves. At night these yews are said to rise up and walk across the valley, shape-shifting and shape-changing into ghostly marauders. ${ }^{14}$

The first stage of the project resulted in documentary pictures of various sites. The landscape acted as a symbol of myth, the unknown and unseeable. Forests featured heavily in my quest to represent the supernatural. In his early twentieth century publication The Lore of the Forest, Alexander Porteous notes: 
In the early age the forests and woods were imbued with a certain degree of mystery, intensified, no doubt, by the deep and solemn shadows which lay hidden in its depths. They were believed to be peopled with crowds of strange beings endowed with superhuman powers and characters. ${ }^{15}$

Could a photograph show this, without resorting to the more staged or constructed methods described earlier? I experimented by placing text below each image to explain the supernatural occurrence. However this strategy was unsuccessful, as I wanted to use the photograph alone to communicate the unseen.

The second stage in the development of my project was to consider layering two images, or two realities. I needed a vehicle to allow the viewer to inhabit two worlds: that of the real and familiar, and the realm of myth. Double exposure proved an interesting way of presenting the everyday and the otherworldly. Image 2 shows the final use of the yew tree forest depicted in Image 1, merged with a familiar, homely attic room.

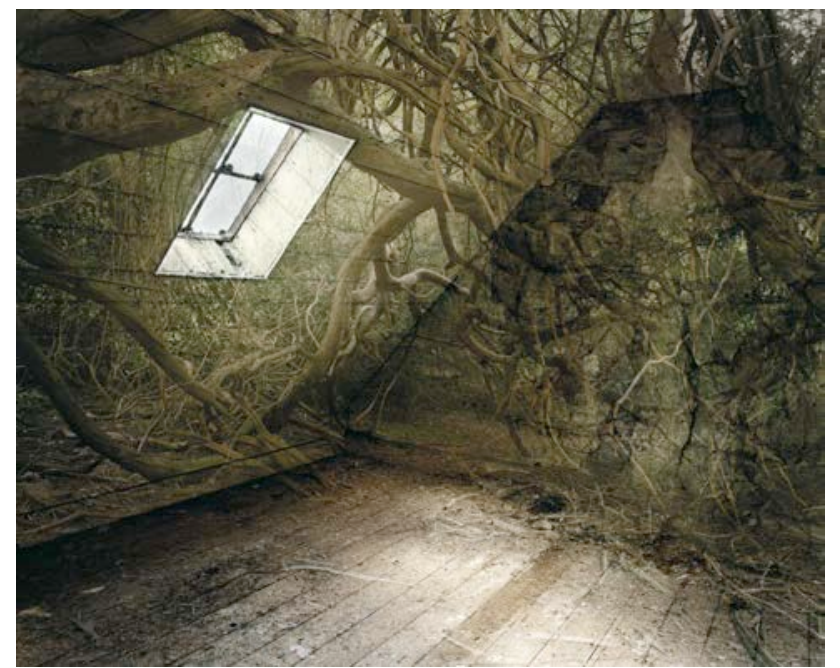

Image 2 - Carolyn Lefley, 'Realm XI (Shapeshifter)', 2009 - 2013. Reproduced with permission from the artist.

My approach took inspiration from the fictional literature of C.S. Lewis, George MacDonald and J.R.R. Tolkien who through fictional prose weave locations of myth and the familiar together. Common in these authors is the use of mythopoeia: the idea of creating fictional realms and in essence writing new mythology. These authors invent parallel worlds of fantasy and these adventures nearly always begin in the home. This quote is taken from C S Lewis' The Lion, 
The Witch and The Wardrobe, where the kingdom of Narnia is entered through an ordinary wardrobe:

(Lucy) looked back over her shoulder and there, between the dark tree-trunks, she could still see the open doorway of the wardrobe and even catch a glimpse of the empty room from which she had set out. ${ }^{16}$

In Realm the interior of the home, the real and familiar, acts a portal into a mythical realm. John Berger describes the home as the centre of our world, in an ontological sense. Our home is the heart of our real. ${ }^{17}$ Berger notes: 'Without a home at the center of the real, one is not only shelter-less, but also lost in nonbeing, in unreality. Without a home everything is fragmentation'. ${ }^{18}$

These interiors were photographed in the rural Highlands of Scotland. What interested me about these neglected homes were the traces left behind - the echo of generations gone by. Robert Ginsberg notes in The Aesthetics of Ruins, that the ruin of an ordinary home strikes many chords in our sensibility, since we are familiar with the functions and furnishings' ${ }^{19}$ In these croft house interiors I could imagine how families would have gathered around the hearth to listen to stories of local folklore, passed through generations by the oral tradition of storytelling.

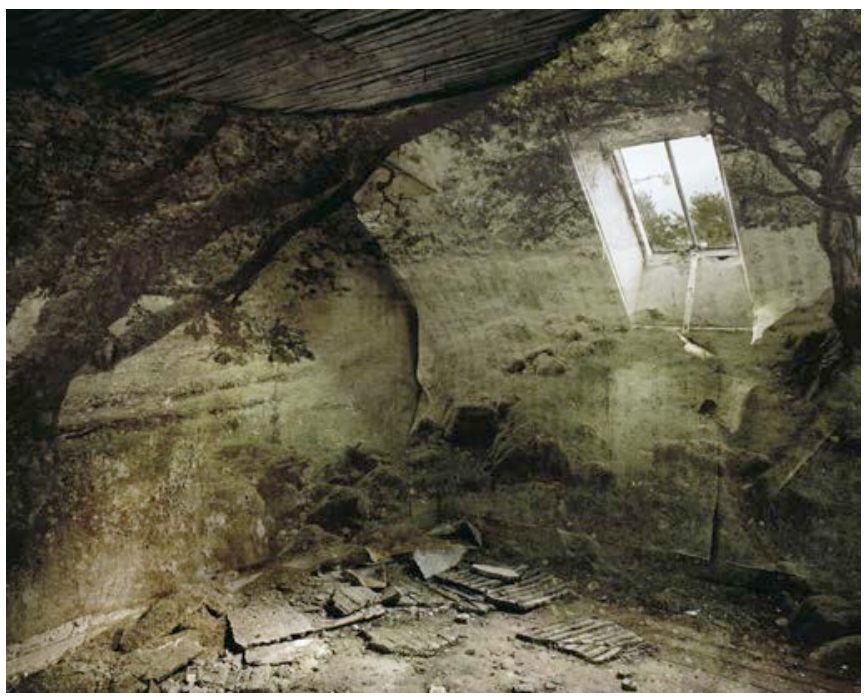

Image 3 - Carolyn Lefley, 'Realm I (The Faerie Glen)', 2009 - 2013. Reproduced with permission from the artist. 
Just as a painter builds up elements of a picture, I used computer software to layer these two scenes. The first image: the abandoned home, in which nature had started to take over. The second image: the realm of the supernatural - represented by the sites of folklore.

The landscape element of Image 3 is the Faerie Glen, on the Isle of Skye, a surreal terrain of miniature grassy mounds and forested groves. In the oral tradition of story telling, these mounds were the domain of the fairy folk or the daoine sith (literally people of the mounds), who were said to live underground coexisting with humankind in a parallel realm of the 'otherworld'. ${ }^{20}$

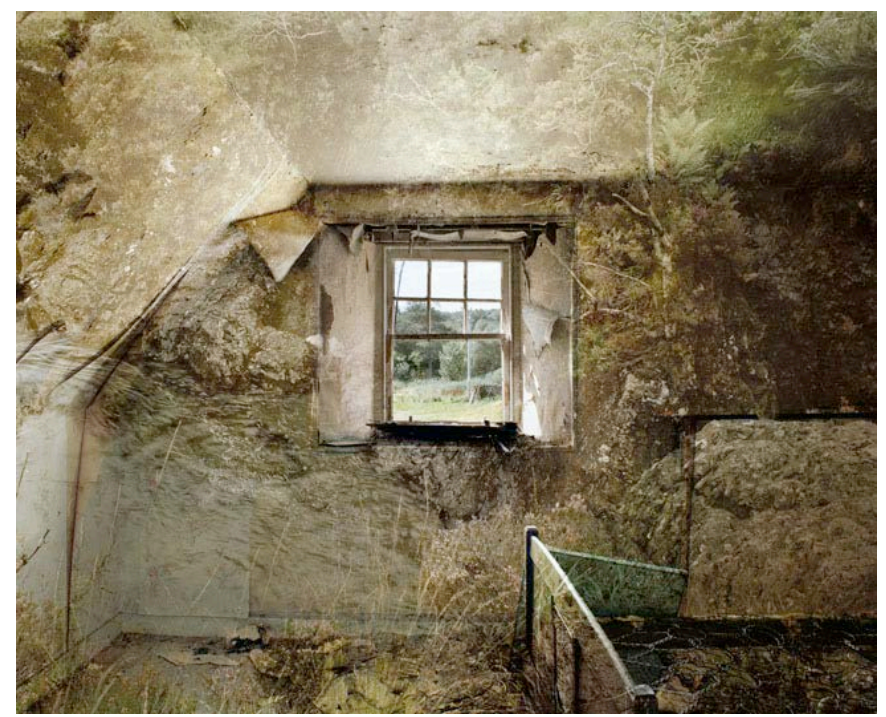

Image 4 - Carolyn Lefley, 'Realm II (The Fairy Pools)', 2009 - 2013. Reproduced with permission from the artist.

Image 4 is entitled: The Fairy Pools. The double exposure in this picture includes a surge of water flowing into the room, adding to the movement of the peeling wallpaper. The bed now almost floats along the flowing water and away from the picture edge. The Fairy Pools are a series of aqua-blue plunge pools and waterfalls, on the Isle of Skye. Local folklore describes these as enchanted pools, said to extend the lifespan of a mortal who bathes there.

The projected, otherworldly scene merges with the crumbling familiarity of the home. Through digital double exposures the photographic image displays two worlds in parallel. However, regardless of what I sought to symbolise, these landscape scenes are real places, used here to represent the unseeable. What if it was possible to photograph a completely unreal place or a supernatural happening? This quest to picture the unseen or unbelievable, taken up by the famous hoaxers 
mentioned earlier, using lo-fi techniques, has now been taken to a higher level of viewer deception with the use of computer generated imagery (CGI).

\section{A new era for photography: computer generated imagery (CGI)}

Talented CGI artists can construct images that simulate a photo-real look but depict scenes that can be completely fantastical. In many cases it is difficult to differentiate now between a computer-simulated photograph and a photograph of reality. This development has grown out of the motion picture industry, with pioneering CGI and live-action films such as Jurassic Park (1993), forging a new visual language for cinema. This has in turn influenced commercial product photography, for example the majority of car advertisements are now created with CGI. Expensive products can be now 'photographed' before they are even produced, to market to a global audience, unaware they are viewing a computer simulation. This is all possible because of what Lev Manovich calls 'the paradox of digital visual culture'. ${ }^{21}$ Whilst computer simulated imaging is becoming more prevalent, the style is aims to mimic the photographic and not human vision. ${ }^{22}$ Manovich explains:

...the reason we may think that computer graphics has succeeded in faking reality is that we, over the course of the last hundred and fifty years, have come to accept the image of photography and film as reality. What is faked is only a film-based image. Once we came to accept the photographic image as reality, the way to its future simulation was open. ${ }^{23}$

CGI artists aspire to create a photo-real image, and are not so concerned with actual reality. Does this create a new language for the photograph, once held up as a window to reality? Sarah Kember considers this is her book Virtual Anxiety:

How can we panic about the loss of the real when we know (tacitly or otherwise) that the real is always already lost in the act of representation. Any representation, even a photographic one, only constructs an image-idea of the real; it does not capture it, even though it might seem to do so. ${ }^{24}$

However the wholly computer generated photograph is not a traditional photograph, it is not a 'trace' of reality. The photo-real computer generated image occupies a new in-between state between the real and the simulated, between truth and deception. There is a huge potential for visual artists to utilise this new technology to create new worlds and persuade the viewer of new truths.

To conclude, I have discussed the idea of the photograph as a vehicle for representing the unseeable. I have explored the ontology of the photograph and its 
capacity to represent myth, discussing famously faked images of the supernatural. My project 'Realm' has been described as a case study for the picturing of mythology and the supernatural. The photographic image, whether constructed with hoax elements or generated wholly in the computer, is still a trusted medium. The photograph, whatever its provenance, has an inherent ontological quality which can deceive and persuade the viewer.

\section{Notes}

${ }^{1}$ Susan Sontag, On Photography (London: Penguin, 2002), 154.

${ }^{2}$ André Bazin, 'The Ontology of the Photographic Image', trans. Hugh Gray, Film Quarterly, Vol.13, No.4. (1960), 7-8.

${ }_{3}^{3}$ Arthur Conan Doyle, The Coming of the Fairies (New York: George H. Doran Company, 1921), v.

${ }^{4}$ Ibid., 31 .

${ }^{5}$ Ibid,. 44.

${ }^{6}$ Magnus Magnusson, Fakers, Forgers \& Phoneys (Edinburgh: Mainstream Publishing, 2006), 105.

${ }^{7}$ Joe Nickell, Camera Clues: A Handbook for Photographic Investigation (The University Press of Kentucky, 1994), 171.

${ }^{8}$ Ibid.

${ }^{9}$ James Meikle, 'Loch Ness monster picture is a fake, photographer admits', The Guardian (4 October 2013), Viewed 14 July 2014,

$<$ http://www.theguardian.com/uk-news/2013/oct/04/loch-ness-monster-picturefake>.

${ }^{10}$ Ibid.

${ }^{11}$ Sontag, On Photography, 52.

${ }^{12}$ Sigmund Freud, 'The Uncanny', in The Standard Edition of the Complete Psychological Works of Sigmund Freud. Vol. XVII, ed. \& trans. James Strachey (London: Hogarth, 1953), 220.

13 'Definition of myth in English', Viewed 14 July 2014, $<\mathrm{http}$ ://www.oxforddictionaries.com/definition/english/myth $>$

${ }^{14}$ Jo Bourne, The Most Amazing Haunted and Mysterious Places in Britain (London: The Readers Digest Association Ltd, 2009), 81.

${ }^{15}$ Alexander Porteous, The Lore of the Forest (London: Senate, 1996), 84.

${ }^{16}$ C. S. Lewis, The Lion, the Witch and the Wardrobe (Harmondsworth, Eng.: Penguin, 1959), 13.

${ }^{17}$ John Berger, And Our Faces, My Heart, Brief as Photos (London: Writers and Readers, 1984), 56.

${ }^{18}$ Ibid.

${ }^{19}$ Robert Ginsberg, The Aesthetics of Ruins (Kenilworth: Rodopi, 2004), 370. 
${ }^{20}$ W.Y. Evans-Wentz, The Fairy-Faith in Celtic Countries (London, New York, Toronto, Melbourne: Oxford University Press: 1911), 100.

${ }^{21}$ Lev Manovich, The Language of New Media (Cambridge, Massachusetts; London, England: The MIT Press, 2001), 180.

22 Ibid.

${ }^{23}$ Ibid., 200.

${ }^{24}$ Sarah Kember, Virtual Anxiety: Photography, New Technologies and Subjectivity (Manchester University Press: 1998), 17.

\section{Bibliography}

Bazin, André. 'The Ontology of the Photographic Image'. Translated by Hugh Gray. Film Quarterly, Vol.13, No.4. (1960), 4-9.

Berger, John. And Our Faces, My Heart, Brief as Photos. London: Writers and Readers, 1984.

Bourne, Jo. The Most Amazing Haunted and Mysterious Places in Britain. London: The Readers Digest Association Ltd, 2009.

Conan Doyle, Arthur. The Coming of the Fairies. New York: George H. Doran Company, 1921.

Evans-Wentz, W.Y.. The Fairy-Faith in Celtic Countries. London, New York, Toronto, Melbourne: Oxford University Press: 1911.

Freud, Sigmund. 'The Uncanny'. In The Standard Edition of the Complete Psychological Works of Sigmund Freud. Vol. XVII. Edited and translated by James Strachey, 219-252. London: Hogarth, 1953.

Ginsberg, Robert. The Aesthetics of Ruins. Kenilworth: Rodopi, 2004.

Kember, Sarah. Virtual Anxiety: Photography, New Technologies and Subjectivity. Manchester University Press: 1998.

Lewis, C. S.. The Lion, the Witch and the Wardrobe. 1950. Reprint, Harmondsworth, Eng.: Penguin, 1959.

Magnusson, Magnus. Fakers, Forgers \& Phoneys. Edinburgh: Mainstream Publishing, 2006.

Manovich, Lev. The Language of New Media. Cambridge, Massachusetts; London, England: The MIT Press, 2001. 
Meikle, James. 'Loch Ness monster picture is a fake, photographer admits'. The Guardian, 4 October 2013. Viewed 14 July 2014.

$<$ http://www.theguardian.com/uk-news/2013/oct/04/loch-ness-monster-picturefake>.

Nickell, Joe. Camera Clues: A Handbook for Photographic Investigation. The University Press of Kentucky, 1994.

Porteous, Alexander. The Lore of the Forest. London: Senate, 1996.

Sontag, Susan. On Photography. 1977. Reprint, London: Penguin, 2002.

Carolyn Lefley is Lecturer in Photography at the University of Hertfordshire and a photographic artist. Her research interests include photography and expanded media: moving image, mobile photography and computer generated imagery. Her photographic practice explores notions of home, belonging and folklore. 